\title{
Clinical predictors of abnormal head computed tomography scan in patients who are conscious after head injury
}

\author{
Rakesh Kumar Mishra, Ashok Munivenkatappa', Vasuki Prathyusha², Dhaval P. Shukla, Bhagavatula Indira Devi \\ Departments of Neurosurgery and ${ }^{2}$ Biostatistics, National Institute of Mental Health and Neurosciences, Bengaluru, Karnataka, ${ }^{1}$ National \\ Institute of Epidemiology (ICMR), Chennai, Tamil Nadu, India
}

\begin{abstract}
Background: Indication of a head computed tomography (CT) scan in a patient who remains conscious after head injury is controversial. We aimed to determine the clinical features that are most likely to be associated with abnormal CT scan in patients with a history of head injury, and who are conscious at the time of presentation to casualty. Materials and Methods: This is a prospective observation study of patients presented to casualty with history of head injury, and who were conscious, i.e., Glasgow Coma Scale (GCS) 15 at the time of evaluation. All patients underwent head CT scan. The CT scan was reported as abnormal if it showed any pathology ascribed to trauma. The following variables were used: age, gender, mode of injury (road traffic accident, fall, assault, and others), duration since injury, and history of transient loss of consciousness, headache, vomiting, ear/nose bleeding, and seizures. Logistic regression analysis was used to identify the clinical features that predicted an abnormal CT scan. Results: During the observation period, a total of 1629 patients with head injury were evaluated, out of which 453 were in GCS 15 . Abnormal CT scan was present in $195(43 \%)$ patients. Among all the variables, the following were found significantly associated with abnormal CT scan: duration since injury (>12 h) $P<0.001$; vomiting odds, ratio (OR) 1.89 (1.23, 2.80), $P<0.001$; and presence of any symptom, OR $2.36(1.52,3.71), P<0.001$. Conclusion: A patient with GCS 15 presenting after 12 hours of injury with vomiting or combination of symptoms has a significant risk of abnormal head CT scan.
\end{abstract}

Key words: Head computed tomography scan, mild traumatic brain injury, minor head injury, skull fracture, traumatic intracranial lesion

\section{Introduction}

Patients often present with minor head injury in trauma and emergency departments. The brain computed tomography (CT) scan is a investigation of choice to diagnose intracranial lesions in such patients. ${ }^{[1]}$ Fifteen percent of patients with mild traumatic brain injury (mTBI) have intracranial lesions in CT scan, among them $<1 \%$ require any neurosurgical intervention. ${ }^{[2]}$ However, the indications for a CT scan is debatable if the patient has

\section{Address for correspondence:}

Dr. Dhaval P. Shukla, Department of Neurosurgery, National Institute of Mental Health and Neurosciences, Bengaluru, Karnataka, India.

E-mail: neurodhaval@rediffmail.com

\begin{tabular}{|l|l|}
\hline \multicolumn{2}{|c|}{ Access this article online } \\
\hline Quick Response Code: & Website: \\
\hline & www.ruralneuropractice.com \\
\hline & \\
\hline
\end{tabular}

Glasgow Coma Scale (GCS) 15 at the time of presentation. In various guidelines, the indication of $\mathrm{CT}$ scan varies on a number of clinical predictors. ${ }^{[3-5]}$ In resource-constrained settings, indication for CT scan for patients with GCS 15 needs to be better defined. ${ }^{[6,7]}$ Various clinical predictors have been used in earlier studies to determine the indications of CT scan in patients with mTBI, but most of them have not been validated in external settings. ${ }^{[8-13]}$ The aim of the present study was to determine presence of any clinical variable that serves as a risk factor for abnormal head CT in a patient with head injury with GCS 15, which may help in formulating guidelines for the management of TBI in our country and also help in the prioritization of resources in the community.

This is an open access article distributed under the terms of the Creative Commons Attribution-NonCommercial-ShareAlike 3.0 License, which allows others to remix, tweak, and build upon the work non-commercially, as long as the author is credited and the new creations are licensed under the identical terms.

For reprints contact: reprints@medknow.com

How to cite this article: Mishra RK, Munivenkatappa A, Prathyusha V, Shukla DP, Devi BI. Clinical predictors of abnormal head computed tomography scan in patients who are conscious after head injury. J Neurosci Rural Pract 2017;8:64-7. 


\section{Materials and Methods}

This study was conducted at a Level I neurotrauma center. Patients with head injury were evaluated by neurosurgery residents and data were entered in a structured "head injury proforma," which consists of comprehensive clinical and head CT scan findings. The data were verified by a qualified neurosurgeon on duty. Data of all patients with head injury with GCS score 15, over a period of $2 \frac{1}{2}$ months were prospectively studied. CT scan findings were confirmed independently from images archived in the picture archival communication system of the institute by the senior author (DS). We used 15 point GCS for all patients. ${ }^{[14]}$ To identify the predictors of our dependent variable "CT scan finding," it was categorized as normal or abnormal. The abnormal CT scan was defined as any finding ascribed to head trauma including skull fracture, cerebral edema, epidural hematoma, subdural hematoma, cerebral contusion, intracerebral hematoma, intraventricular hemorrhage, and subarachnoid hemorrhage. The person reporting head CT scan was blinded to clinical findings. It was independently verified by blinding to GCS by one of the authors. The variables used for the analysis were age in years $(<40,41-60,>60)$, gender, mode of injury (road traffic accident (RTA), fall, assault, and other), duration since injury in hours $(<6,6-12,>12)$, and following symptoms: loss of consciousness (LOC), headache, vomiting, ear/nose bleed, and seizures.

\section{Statistical methods}

The analysis was performed with the SPSS version 15 (SPSS, Inc., Chicago, IL, USA; Network license, serial number 5047404). Data were expressed using descriptive statistics such as mean, standard deviation for continuous variables, frequency, and percentage for categorical variables. Statistical analysis was done using Chi-square test for categorical variables, and Mann-Whitney U-test for continuous variables with $5 \%$ significance level. Unpaired two-tailed $t$-test used for mean age. Chi-square test used for age category, duration, and mode of injury. Chi-square test with Mid-P exact used for gender and symptoms. Logistic regression analysis was applied to arrive at the equation to find the probability of having an abnormal head CT scan based on the clinical predictors.

\section{Results}

A total of 1,629 patients with TBI were evaluated during the study period of $2 \frac{1}{2}$ months, and 453 patients with GCS 15 at the time of presentation to casualty were identified. The mean age of the patients was
$32.84 \pm 17.46$ years, and male to female ratio was $4: 1$. RTAs were the major cause of injury accounting for $53 \%$, followed by assault (31\%), falls (13.2\%), and others (2.8\%). Three hundred and twenty-seven (72.2\%) patients had at least one of the following four symptoms: LOC, vomiting, ear/nose bleeding, or seizure following the head injury. Transient LOC lasting $<30 \mathrm{~min}$ was most common symptom reported by $43 \%$ patients followed by vomiting (36\%), ear/nose bleed (18.5\%), and seizure (4.4\%). The most common combination of symptoms was LOC and vomiting. The CT was abnormal in $43 \%$ of patients. The demographic and clinical details of patients with normal and abnormal CT scan are compared in Table 1. Details of abnormal CT scan findings are shown in Table 2. Twenty-two (5\%) patients underwent surgery for the traumatic lesion. Significantly more number of patients with age $<40$ years had a normal CT scan. Significantly more number of patients with duration of $<6 \mathrm{~h}$ after injury had a normal CT scan. The presence of any symptom had an odds ratio (OR) of 2.36 (95\% confidence interval [CI] 1.52, 3.71), $P<0.001$ for a positive CT scan, which was significant. Among individual symptoms, only vomiting was significantly associated with abnormal CT scan, OR 1.89 (95\% CI 1.23, $2.80), P<0.001$. Logistic regression analysis applied on the test yielded the following equation:

$P=1 /\left(1+\mathrm{e}^{-\operatorname{logit}(\mathrm{p})}\right)$

$P=$ Probability of abnormal head CT scan

$\operatorname{logit}(\mathrm{p})=-1.258+(0.247 \times$ duration $6-12 \mathrm{~h}$ or $0.797 \times$ duration $>12 \mathrm{~h})+0.618 \times$ any symptom $+0.321 \times$ vomiting $+(0.519 \times$ age $[41-60]$ or $0.731 \times$ age $(>60))$.

Table 3 shows the accuracy of this equation to predict abnormal CT scan in patients with GCS 15 after head injury. The sensitivity is $63.72 \%(58.16-69.02 \%)$, specificity $58.82 \%$ (50.07-67.19\%), positive predictive value $78.29 \%(72.76-83.17 \%)$, and negative predictive value $41.03 \%$ (34.05-48.28\%) for prediction of abnormal head CT scan.

\section{Discussion}

Head injuries are commonly managed in the trauma and emergency departments, among them $70-80 \%$ are mild in nature. ${ }^{[15]}$ Many head injured patients are conscious on arrival to casualty and do not have a neurological deficit. However, such a patient constitutes a potential problem for neurosurgeons because a patient with an apparent minor head injury can rarely develop an intracranial hematoma, deteriorate, and die. There is 
Table 1: Comparison of variables between normal and abnormal computed tomography scan

\begin{tabular}{|c|c|c|c|c|c|}
\hline & Normal CT $(n=258)$ & Abnormal CT $(n=195)$ & Total (453) & $P$ & OR $(95 \% \mathrm{CI})$ \\
\hline Age in years, mean (SD) & $31.79(16.12)$ & $34.3(19.03)$ & $32.84(17.46)$ & 0.13 & \\
\hline$\leq 40$ & 201 & 130 & 331 & 0.02 & \\
\hline $41-60$ & 43 & 46 & 89 & & \\
\hline$>60$ & 14 & 19 & 33 & & \\
\hline \multicolumn{6}{|l|}{ Duration (h) } \\
\hline$\leq 6$ & 156 & 88 & 244 & $<0.001$ & \\
\hline $6-12$ & 60 & 46 & 106 & & \\
\hline$>12$ & 42 & 61 & 103 & & \\
\hline \multicolumn{6}{|l|}{ Gender } \\
\hline Male & 207 & 160 & 367 & 0.31 & $0.89(0.55-1.43)$ \\
\hline Female & 51 & 35 & 86 & & \\
\hline \multicolumn{6}{|l|}{ Mode of injury } \\
\hline RTA & 129 & 113 & 242 & 0.19 & \\
\hline Fall & 39 & 21 & 60 & & \\
\hline Assault & 84 & 57 & 141 & & \\
\hline Others & 6 & 4 & 10 & & \\
\hline \multicolumn{6}{|l|}{ Symptoms } \\
\hline Combination of any symptoms & 168 & 159 & 327 & $<0.001$ & $2.36(1.52-3.71)$ \\
\hline Loss of consciousness & 104 & 90 & 194 & 0.1 & $1.27(0.87-1.85)$ \\
\hline Vomiting & 78 & 88 & 166 & $<0.001$ & $1.89(1.23-2.80)$ \\
\hline Bleeding & 44 & 40 & 84 & 0.17 & $1.25(0.78-2.02)$ \\
\hline Seizure & 10 & 10 & 20 & 0.26 & $1.34(0.53-3.37)$ \\
\hline
\end{tabular}

SD: Standard deviation, CT: Computed tomography, RTA: Road traffic accident, OR: Odds ratio, Cl: Confidence interval

Table 2: Abnormal computed tomography (CT) scan findings: $n=195$ (43.05\%)

\begin{tabular}{lc}
\hline CT scan findings & Number (\%) \\
\hline Contusion & $52(26.6)$ \\
Extradural hemorrhage & $29(14.87)$ \\
Subdural hemorrhage & $29(14.87)$ \\
Subarachnoid hemorrhage & $28(14.3)$ \\
Edema & $40(20.5)$ \\
Fracture & $86(44.10)$ \\
Pneumocephalus & $21(10.7)$ \\
\hline
\end{tabular}

Table 3: Accuracy of prediction of abnormal CT scan

\begin{tabular}{lccc}
\hline Observed CT scan & \multicolumn{2}{c}{ Predicted CT scan } & Percentage correct \\
\cline { 2 - 3 } & Normal & Abnormal & \\
\hline Normal & 202 & 56 & 78.3 \\
Abnormal & 115 & 80 & 41.0 \\
Overall percentage & & & 62.3 \\
\hline \multicolumn{2}{l}{ CT: Computed tomography. Hosmer and Lemeshow Test, Chi-square 3.307, }
\end{tabular}

CT: Computed tomography. Hosmer and Lemeshow Test, Chi-square 3.307, df 8 , significance 0.914

controversy regarding the policy for hospital admission and evaluation with CT scan for these patients. A CT scan is desirable for patients with minor head injury as it is useful for detection of a clinically significant intracranial lesion, prognostication, and decision for discharge. To obviate unnecessary CT scans, many guidelines are available for indication of CT scan for minor head injury in adults. ${ }^{[16]}$ Among these, Canadian CT Head Rule is the most widely validated rule, with a sensitivity of $99-100 \%$ and a specificity of $48-77 \% .^{[16-18]}$ Other rules differ considerably in population, predictors, outcomes, methodologic quality, and performance. Many of them are not validated in a separate population, and their impact on practice has not been assessed. In our patient population, only four symptoms were present: vomiting, LOC, ear/nose bleeding, and seizures. We did not include scalp injury as a variable because it has little diagnostic value. ${ }^{[18]}$ We do not perform coagulation profile for patients with minor head injury at our institute; hence, we did not include this variable. Posttraumatic amnesia (PTA) is also an important predictor of abnormal CT scan. ${ }^{[16]}$ The timing of resolution of PTA is difficult to assess in the emergency department; hence, we did not include this variable as well. We included all CT scan findings attributed to trauma including skull fracture as inclusion criteria for an abnormal (positive) CT scan. We found that presence of any of the symptoms attributed to head injury such as LOC, vomiting, ear/nose bleeding, or seizures predicted an abnormal CT scan. Particularly vomiting after head injury was significantly associated with abnormal CT scan. Although the sensitivity of our prediction model was low, the specificity was higher than most of the available prediction rules. We had some limitations with our study as can be seen with the number of clinical predictors used in the study. Further, this study does not take children into a different group, very often children have different clinical predictor rules for CT scan. We did not define separate significant intracranial injury, which probably has more bearing on management and prognosis. However, the presence of any abnormality 
on CT scan requires neurological observation. Our study needs to be conducted in a larger population and needs to be validated in external settings. However, in spite of these limitations, our study answers one important question for neurosurgeons. What clinical predictors can be used to address the question that "should a patient be shifted to higher center for head CT scan, if the treating center does not have CT scan facility?" Yes, if the patient is older than 40 years of age and has any of following symptoms: vomiting, LOC, ear/nose bleeding, and seizures after head injury he/she should undergo a head CT though not all patients have an abnormal scan.

\section{Conclusion}

We attempted to develop a clinical prediction rule for abnormal CT scan in a patient who is conscious at the time of presentation to casualty after minor head injury. Our prediction rule had low sensitivity but better specificity than the available prediction rules. Our prediction rule can be used to develop guidelines for indication of CT scan in patients with head injury in India if it can be externally validated at various other centers on a larger scale.

\section{Financial support and sponsorship \\ Nil.}

\section{Conflicts of interest}

There are no conflicts of interest.

\section{References}

1. Stein SC, Ross SE. Minor head injury: A proposed strategy for emergency management. Ann Emerg Med 1993;22:1193-6.

2. Bruns JJ Jr., Jagoda AS. Mild traumatic brain injury. Mt Sinai J Med 2009;76:129-37.
3. Smits M, Dippel DW, de Haan GG, Dekker HM, Vos PE, Kool DR, et al. Minor head injury: Guidelines for the use of CT - A multicenter validation study. Radiology 2007;245:831-8.

4. Miller EC, Holmes JF, Derlet RW. Utilizing clinical factors to reduce head CT scan ordering for minor head trauma patients. J Emerg Med 1997;15:453-7.

5. Haydel MJ, Preston CA, Mills TJ, Luber S, Blaudeau E, DeBlieux PM Indications for computed tomography in patients with minor head injury. N Engl J Med 2000;343:100-5.

6. Abdul Latip LS, Ahmad Alias NA, Ariff AR, Shuaib IL, Abdullah J, Naing NN. CT scan in minor head injury: A guide for rural doctors. J Clin Neurosci 2004;11:835-9.

7. Shackford SR, Wald SL, Ross SE, Cogbill TH, Hoyt DB, Morris JA, et al. The clinical utility of computed tomographic scanning and neurologic examination in the management of patients with minor head injuries. J Trauma 1992;33:385-94

8. Stein SC, Burnett MG, Glick HA. Indications for CT scanning in mild traumatic brain injury: A cost-effectiveness study. J Trauma 2006;61:558-66

9. Smits M, Dippel DW, de Haan GG, Dekker HM, Vos PE, Kool DR, et al. External validation of the Canadian CT head rule and the new orleans criteria for CT scanning in patients with minor head injury. JAMA 2005;294:1519-25

10. Eng J, Chanmugam A. Examining the role of cranial CT in the evaluation of patients with minor head injury: A systematic review. Neuroimaging Clin N Am 2003;13:273-82.

11. Smits M, Dippel DW, Nederkoorn PJ, Dekker HM, Vos PE, Kool DR, et al. Minor head injury: CT-based strategies for management A cost-effectiveness analysis. Radiology 2010;254:532-40.

12. Saboori M, Ahmadi J, Farajzadegan Z. Indications for brain CT scan in patients with minor head injury. Clin Neurol Neurosurg 2007;109:399-405.

13. Shiomi N, Echigo T. A guide to initial management of minor head injury. No Shinkei Geka 2004;32:465-70.

14. Middleton PM. Practical use of the Glasgow Coma Scale; a comprehensive narrative review of GCS methodology. Australas Emerg Nurs J 2012;15:170-83.

15. Vos PE, Alekseenko Y, Battistin L, Ehler E, Gerstenbrand F, Muresanu DF, et al. Mild traumatic brain injury. Eur J Neurol 2012;19:191-8.

16. Stiell IG, Wells GA, Vandemheen K, Clement C, Lesiuk H, Laupacis A, et al. The Canadian CT head rule for patients with minor head injury. Lancet 2001;357:1391-6.

17. Stiell IG, Clement CM, Rowe BH, Schull MJ, Brison R, Cass D, et al. Comparison of the Canadian CT head rule and the new orleans criteria in patients with minor head injury. JAMA 2005;294:1511-8.

18. Pandor A, Goodacre S, Harnan S, Holmes M, Pickering A, Fitzgerald P, et al. Diagnostic management strategies for adults and children with minor head injury: A systematic review and an economic evaluation. Health Technol Assess 2011;15:1-202. 